\title{
THE EFFECT OF TEMPERING TEMPERATURE ON CORROSION OF AISI 1045 STEEL IN 1M SODIUM CHLORIDE ENVIRONMENT
}

\author{
0. Awheme ${ }^{1, *}$, G. U. Unueroh ${ }^{2}$ and I. M. Ibrahim ${ }^{3}$ \\ 1,2,3, MECHANICAL ENGINEERING DEPARTMENT, UNIVERSITY OF BENIN, BENIN City, Edo STATE, NIGERIA \\ E-mail addresses: ${ }^{1}$ optimistsdgreat@yahoo.co.uk, ${ }^{2}$ georgina.odin@uniben.edu, ${ }^{3}$ checkisquare@gmail.com
}

\begin{abstract}
The effect of tempering temperature on corrosion of AISI 1045 steel in sodium chloride environment were investigated by means of weight loss measurement (WLM), optical metallography microscopy (OMM) and scanning electron microscopy (SEM) at an interval of 15 days for the period of 90 days. The results showed that corrosion of the tempered steel samples increases with increase in tempering temperatures. The corrosion rate values are between (0.0004-0.0015) g/ $\mathrm{mm}^{2} / \mathrm{yr}$ for control sample which peaked on day 45, $(0.0002-0.0007) \mathrm{g} / \mathrm{mm}^{2} / \mathrm{yr}$ for 250 ${ }^{\circ} \mathrm{C}$ tempered sample which peaked on day $30,(0.0003-0.0008) \mathrm{g} / \mathrm{mm}^{2} / \mathrm{yr}$ for $350^{\circ} \mathrm{C}$ tempered sample which peaked on day 30, (0.0003-0.0012) $\mathrm{g} / \mathrm{mm}^{2} / \mathrm{yr}$ for $450{ }^{\circ} \mathrm{C}$ tempered sample which peaked on day 30 and (0.0003-0.0013) $\mathrm{g} / \mathrm{mm}^{2} / \mathrm{yr}$ for $550^{\circ} \mathrm{C}$ tempered sample which peaked on day 30 . The result obtained showed that control samples were more susceptible to corrosion in $\mathrm{NaCl}$ environment than tempered samples. The least tempered $\left(250{ }^{\circ} \mathrm{C}\right)$ samples have better corrosion resistance than other tempered samples, which revealed that, it is best to be used in this medium compared to other tempered samples and control sample.
\end{abstract}

Keywords: Tempering, AISI 1045 steel, Corrosion, NaCl environment

\section{INTRODUCTION}

In modern industrialization and technological advancement, metals account for over $90 \%$ of equipment composition used for construction [1, 2, 3]. The two particular reasons for the extraordinary versatility of steel are heat treatment and alloying. These procedures alter the crystalline structure of steel, and hence it's physical properties. Medium carbon steel has between $(0.3 \% \mathrm{C}-0.6 \% \mathrm{C})$. The usage of steel is well pronounced in various aspects such as in manufacturing, oil and gas, construction, medical, textile, transport and aviation industries [4]. Medium carbon steel may be heat treated by austenitizing, quenching, and then tempering to improve their mechanical properties. They are most often utilized in the tempered condition, having microstructures of tempered martensite. The plain medium-carbon steels have low hardenabilities and can be successfully heat treated only in very thin sections and with very rapid quenching rates [5]. Additions of chromium, nickel, and molybdenum improve the capacity of these alloys to be heat treated, giving rise to a variety of strengthductility combinations [6]. These heat-treated alloys are stronger than the low-carbon steels, but at a sacrifice of ductility and toughness [7]. Medium carbon steel is suitable for nearly all environments. It is best for the production of machine parts, bolts, crankshafts, gears and railroad. Medium carbon steel main advantage over other metals as plain carbon steel is their low cost of production and they are used successfully where strength and other requirements are not too severe [8].

Failure of parts and components of engineering equipment in different industries by corrosion is one of the major problems. One of the key factors in any corrosion situation is the environment; this has found a wider influence on material strength and performance behaviour. Environment is a variable that can change with time and conditions, its effect on metal corresponds to the micro environmental conditions. Chloride environment is an aggressive solution that affects nearly all common structural materials to some extent $[9,10]$. Two competing processes operate simultaneously in chloride environments.1) the chloride ions activity which tends to destroy the passive film and 2) dissolve oxygen which acts to promote and repair the passive film on metallic materials of construction [11]. However, chloride 
solutions are of high application in most manufacturing and production sector as cleaning agent $[12,13]$. It also has its application in oil and gas exploration, as an important component of drilling fluids in well drilling [14]. It is used to flocculate and increase the density of the drilling fluid to overcome high downwell gas pressure [15]; it is also used to increase the curing of concrete in cemented casting $[16,17]$. It also has its application in the food, medicine and agricultural industry [18]. Corrosion is responsible for so many mishaps that have occurred in the engineering history of man. The steel industry as profitable and important, is plagued by one of the most engineering solution defying problems known to man, called Corrosion [19]. It is inevitable that the industrial performance of a given metal will significantly decrease by exhibiting anodic dissolution or oxidation when an electrochemical reaction occurs. Present day trends in the metal industries are towards improving the surface properties (e.g. corrosion and wear) of materials [20].

Heat treatment of steel is one of the ways of improving its resistance to corrosion [21]. Heat treatment involves the application of heat to a material to obtain desired material properties (e.g. Mechanical, corrosion, electrical, magnetic e-t-c). During the heat treatment process, the material usually undergoes phase microstructural and crystallographic changes and this has effect on the corrosion, mechanical and electrical properties of the steel [22]. Tempering is accomplished by heating a martensitic steel to a temperature below the eutectoid for a specified time. Tempering is carried out at temperatures between $250{ }^{\circ} \mathrm{C}$ and $650{ }^{\circ} \mathrm{C}$ $\left(480{ }^{\circ} \mathrm{F}\right.$ and $1200{ }^{\circ} \mathrm{F}$ ); internal stresses, however, may be relieved at temperatures as low as $200{ }^{\circ} \mathrm{C}$ $\left(390{ }^{\circ} \mathrm{F}\right)$. This tempering heat treatment allows, by diffusional processes, the formation of tempered martensite [7].

Medium carbon steel has wide application in marine environment due to low cost, availability and versatility $[23,24]$. Due to the corrosiveness of the marine environment and the susceptibility of medium carbon steel to corrosion, there is therefore the need to investigate the effect of tempering temperatures on corrosion of AISI 1045 steel in sodium chloride environment.

\section{MATERIAL AND METHODS}

\subsection{Material}

The material used in this investigation is a medium carbon steel substrate of 16 millimeter diameter. The chemical composition of this material were analyzed for by a mass spectrometer analyzer.

\subsection{Methods}

\subsubsection{Preparation of Samples}

The medium carbon steel was machined into a cylindrical piece and cut into 25 pieces. Each sample dimension was $16 \mathrm{~mm}$ in diameter and $40 \mathrm{~mm}$ in length.

\subsubsection{The Heat Treatment}

Twenty samples were placed inside the muffle furnace (electric furnace) and heated to austenitic temperature of $930{ }^{\circ} \mathrm{C}$ and held for 30 minutes for homogenization after which the samples were immediately quenched in water. The samples were then tempered at four different temperatures of $250{ }^{\circ} \mathrm{C}, 350{ }^{\circ} \mathrm{C}, 450{ }^{\circ} \mathrm{C}$, and $500{ }^{\circ} \mathrm{C}$ for one hour. The remaining 5 pieces of the samples were used as control samples, without heat treatment so as to see the effect of corrosion and to compare with tempered samples. Both the control samples and heat treated samples were immersed in the $\mathrm{NaCl}$ medium in well labeled plastic containers.

\subsubsection{Weight Loss Measurement and Determination of Corrosion Rate}

The investigation involved periodic weight loss measurement at an interval of 15 days. Specimens were retrieved, washed properly in water, dried and weighed on a weighing balance to determine the weight loss during exposure as described by [7]. the corrosion rates were calculated for using the relation in Equation (1) as obtained from [8];

$$
C . R=\frac{W}{A \times\left(\frac{T}{365}\right)} \quad\left(\frac{\frac{\mathrm{mg}}{\mathrm{mm}^{2}}}{\mathrm{yr}}\right)
$$

Where: $\mathrm{W}$ is the Weight Loss ( $\mathrm{g}$ ), $\mathrm{A}$ is the Total surface area $\left(\mathrm{mm}^{2}\right)$ and $\frac{T}{365}$ is the Exposure time in days extrapolated to a year

Table 1: Chemical composition of the medium carbon steel substrate

\begin{tabular}{|c|c|c|c|c|c|c|c|c|c|c|c|c|c|}
\hline Elements & $\mathrm{C}$ & $\mathrm{Si}$ & $\mathrm{Mn}$ & S & $P$ & $\mathrm{Cr}$ & $\mathrm{Ni}$ & $\mathrm{Cu}$ & $\mathrm{Nb}$ & $\mathrm{Al}$ & B & $\mathrm{Ti}$ & $\mathrm{Fe}$ \\
\hline Compositi & 0.455 & 0.208 & 0.949 & 0.071 & 0.056 & 0.157 & 0.104 & 0.291 & $<0.000$ & 0.007 & 0.001 & 0.006 & 97.692 \\
\hline on (W \%) & 5 & 0 & 5 & 0 & 5 & 0 & 0 & 5 & 1 & 0 & 5 & 5 & 0 \\
\hline
\end{tabular}




\subsubsection{Metallography}

All the steel samples were prepared for optical microscopy using standard metallographic practice. The surface of the specimens was etched using 3\% Nital to reveal the grain boundaries. The micrography was done with a magnification of $\mathrm{x} 200$.

\subsubsection{Scanning Electron Microscopy (SEM)}

At the completion of the investigation after 90 days, the surfaces of the tempered and control sample were examined by using Phenom Pro-Suite scanning electron microscope (SEM).

\section{RESULTS AND DISCUSSION}

The results of the experimental investigation for each experimental procedure described in section 2.2 are presented and discussed in this section.

\subsection{Results}

The result from the corrosion rate analysis is presented in Figure 1. Figures 2 to 6 show the optical micrographs of the control sample and the varied tempered samples after 90 days in $1 \mathrm{~m} \mathrm{NaCl}$ solution. The SEM photographs of the controlled sample and the varied tempered samples after 90 days in $1 \mathrm{~m} \mathrm{NaCl}$ solutions are presented in Figures 7 to 11.

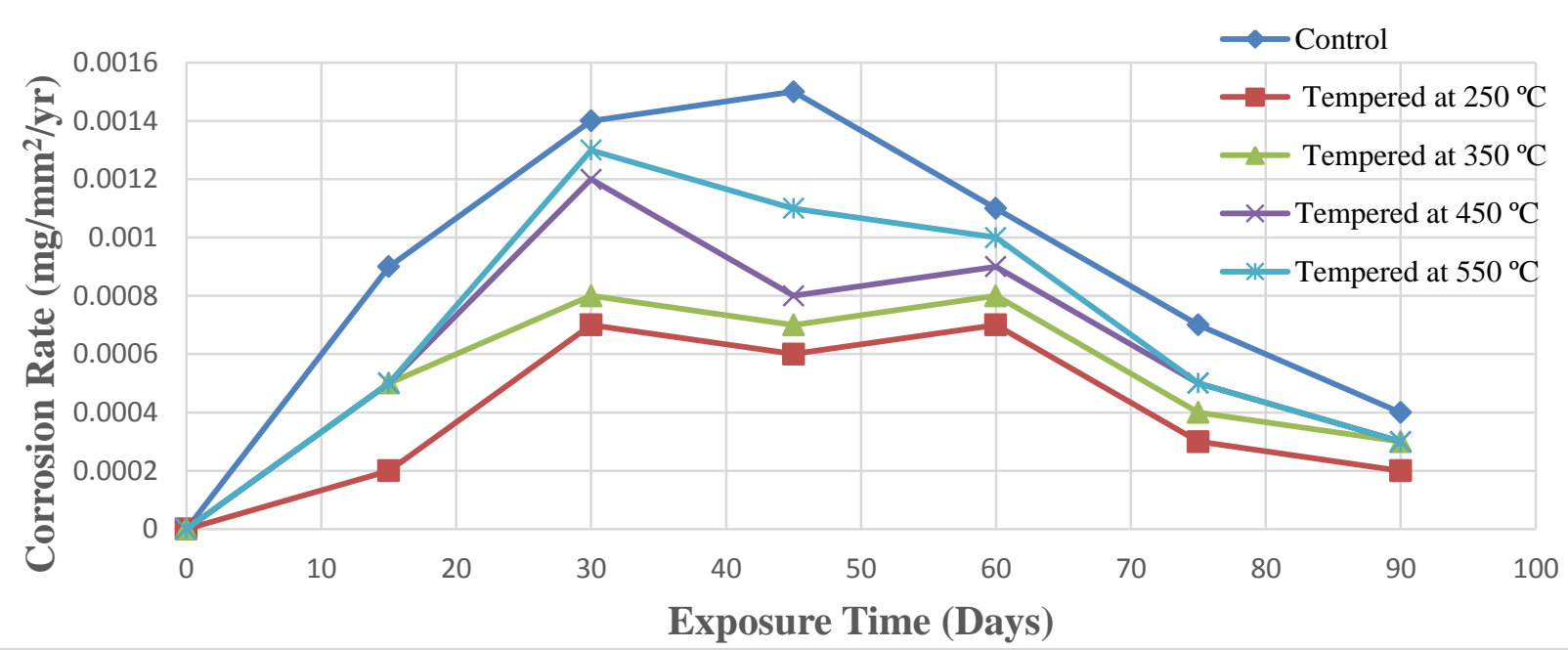

Figure 1: Plot of corrosion rate against exposure time for the steel samples tempered at $250^{\circ} \mathrm{C}-550^{\circ} \mathrm{C}$ temperatures and control sample immersed in $1 \mathrm{M} \mathrm{NaCl}$ for 90 days

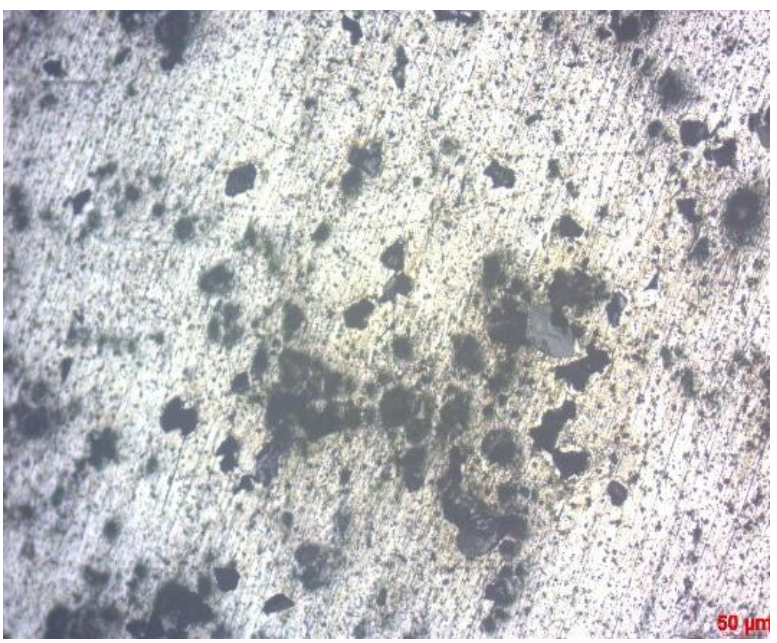

Fig. 2 Optical micrograph of the control sample after 90 days immersion in $1 \mathrm{M} \mathrm{NaCl}$ solution

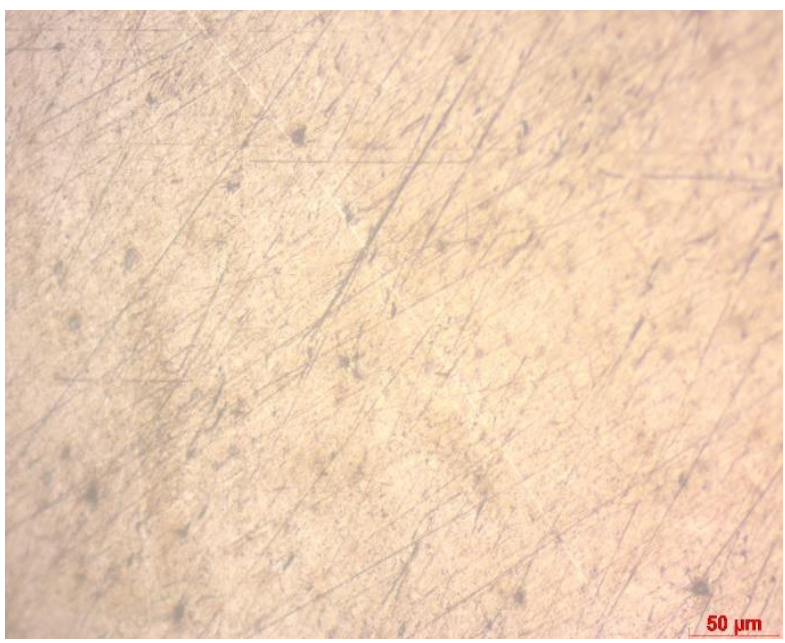

Fig. 3 Optical micrograph of the tempered sample at $250^{\circ} \mathrm{C}$ after 90 days immersion in $1 \mathrm{M} \mathrm{NaCl}$ solution 
The Effect of Tempering Temperature on Corrosion of AiSı 1045 Steel in 1M Sodium Chloride Environ..., O. Awheme, et al.

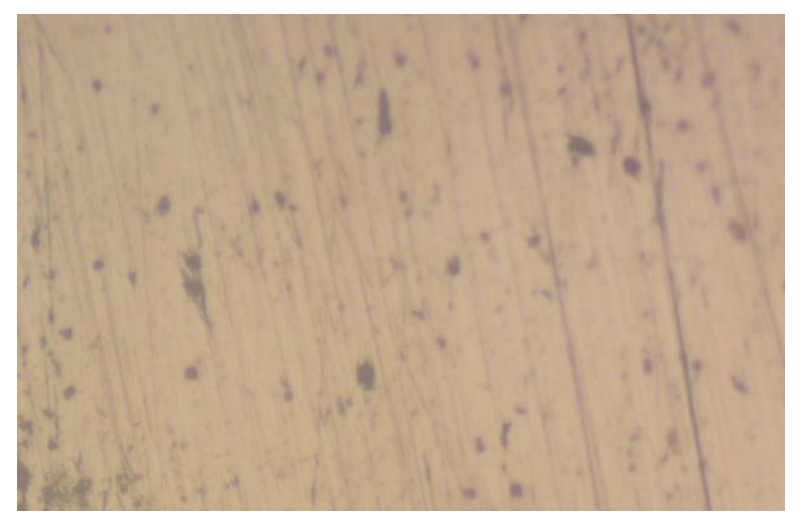

Fig. 4 Optical micrograph of the tempered sample at $350^{\circ} \mathrm{C}$ after 90 days immersion in $1 \mathrm{M}$ NaCl solution

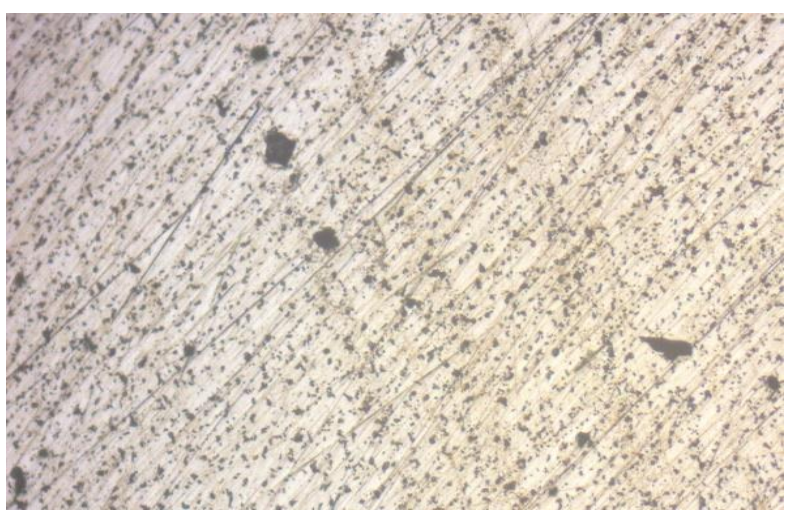

Fig. 5 Optical micrograph of the tempered sample at $450^{\circ} \mathrm{C}$ after 90 days immersion in $1 \mathrm{M} \mathrm{NaCl}$ solution

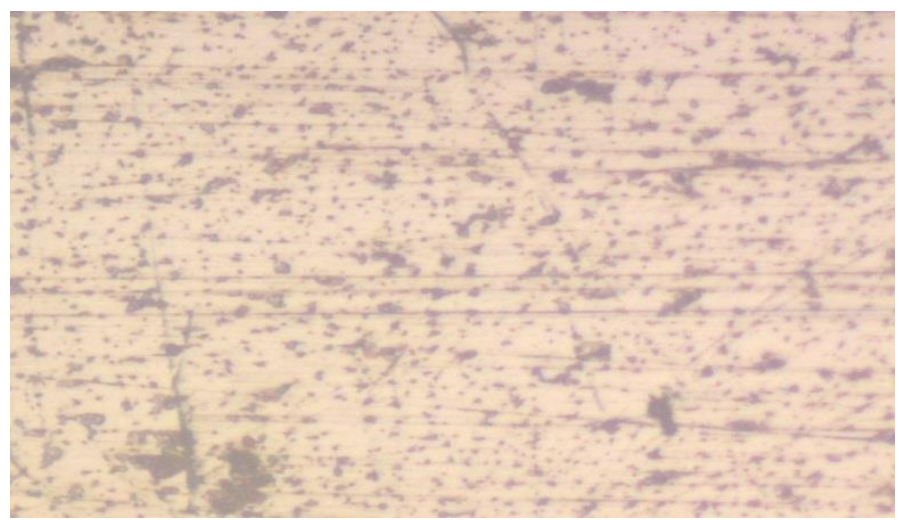

Fig. 6 Optical micrograph of the tempered sample at $550^{\circ} \mathrm{C}$ after 90 days immersion in $1 \mathrm{M} \mathrm{NaCl}$ solution

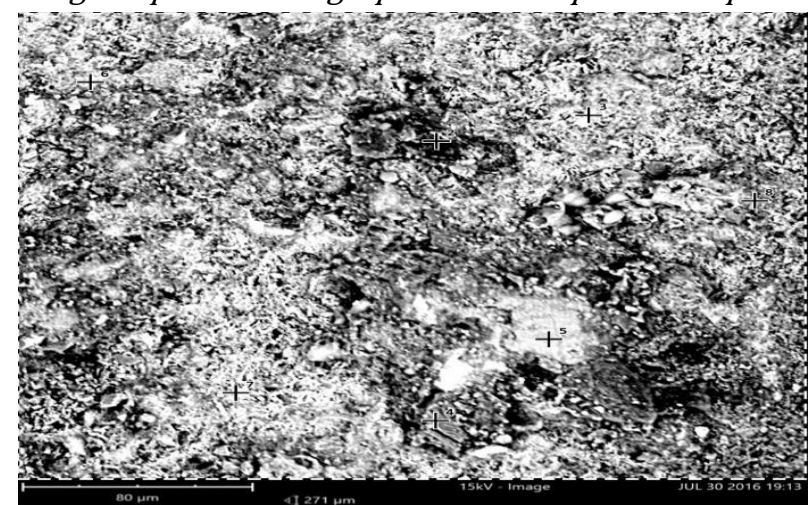

Fig. 7 SEM photograph of the control sample after 90 days immersion in $1 \mathrm{M} \mathrm{NaCl}$ solution

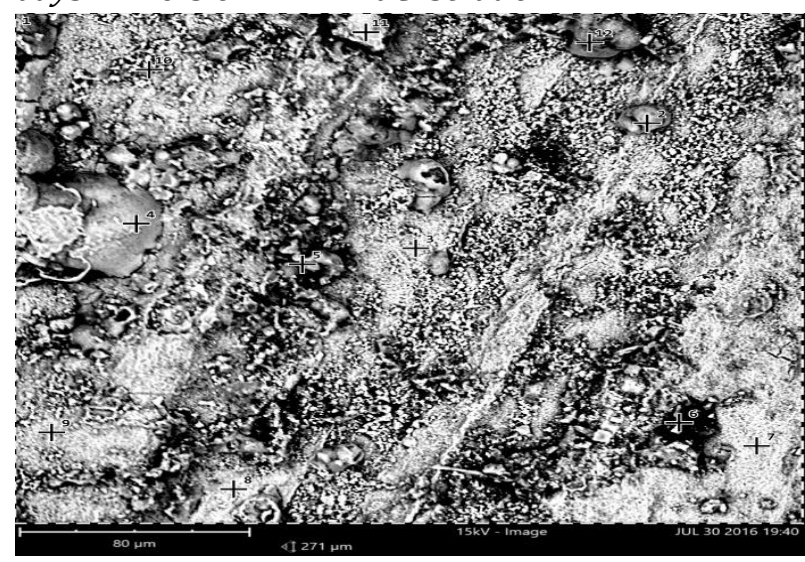

Fig. 9 SEM photograph of the tempered sample at $350^{\circ} \mathrm{C}$ after 90 days immersion in $1 \mathrm{M} \mathrm{NaCl}$ solution

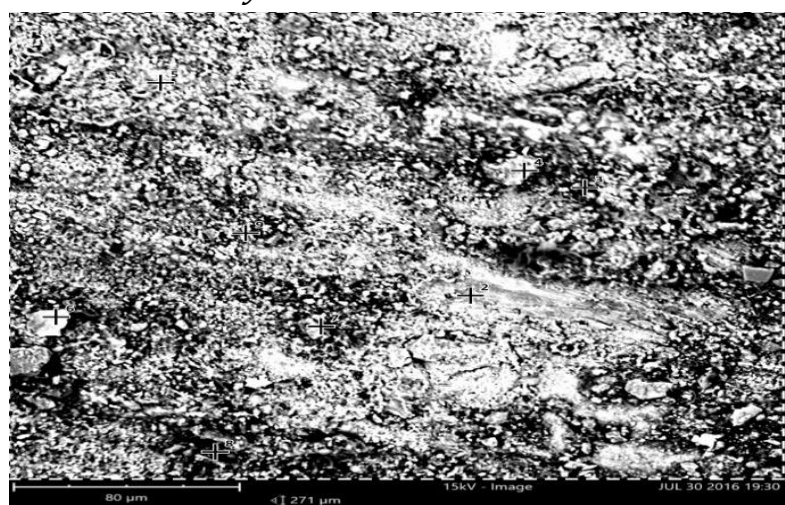

Fig. 8 SEM photograph of the tempered sample at $250^{\circ} \mathrm{C}$ after 90 days immersion in $1 \mathrm{M} \mathrm{NaCl}$ solution

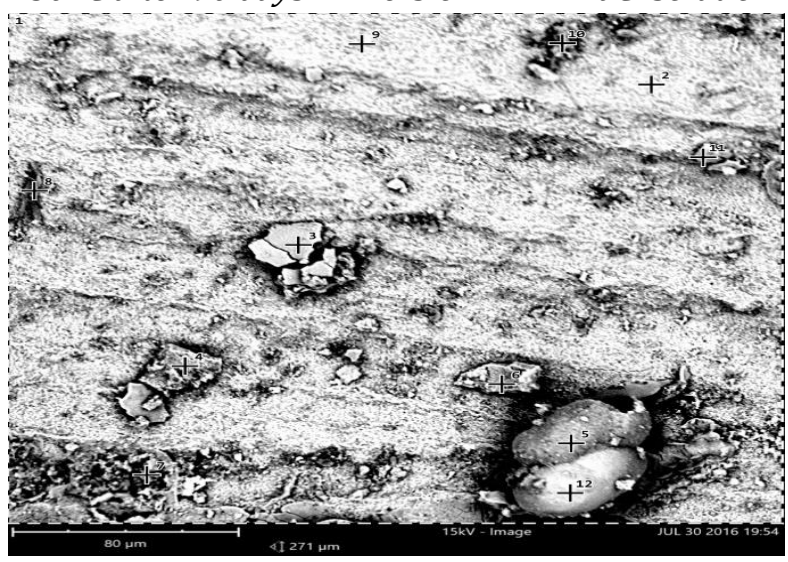

Fig. 10 SEM photograph of the tempered sample at $450^{\circ} \mathrm{C}$ after 90 days immersion in $1 \mathrm{M} \mathrm{NaCl}$ solution 


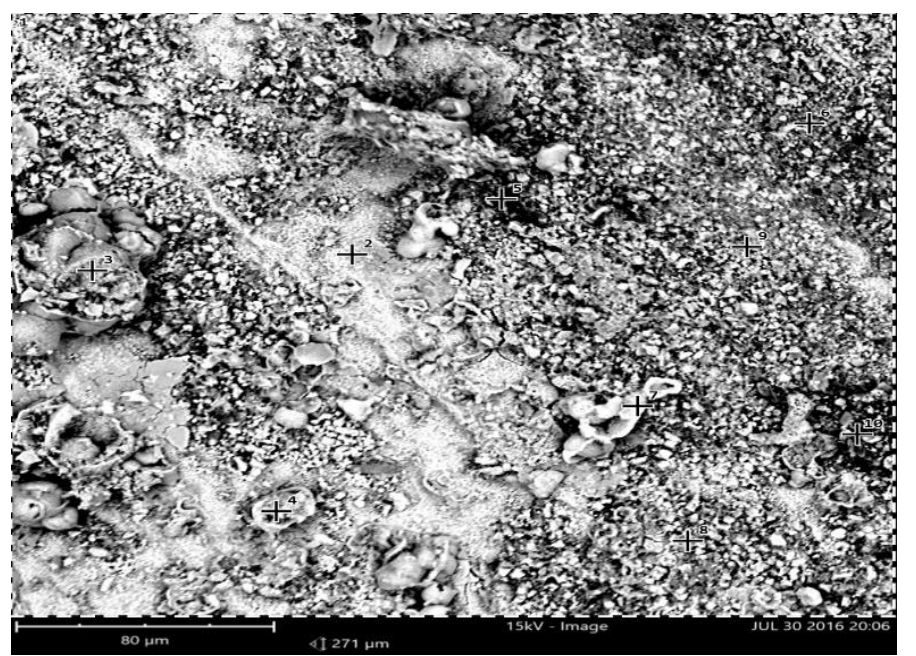

Fig. 11 SEM photograph of the tempered sample at $550^{\circ} \mathrm{C}$ after 90 days immersion in $1 \mathrm{M}$ NaCl solution

\subsection{Discussion}

\subsubsection{Effect of Tempering Temperature on Corrosion Rate}

Fig 1 shows a plot of corrosion rate against exposure time of 90 days. It was observed that the tempered samples have better corrosion resistance than the asreceived (control) sample. This corresponds to the findings in [22]. They observed that the corrosion rate of heat treated specimens in marine medium $(\mathrm{NaCl})$ is low when compared to that of as-rolled steel. It was also observed from the graph that the corrosion rates of all the samples were high between 15 days and 60 days in the corrosive medium and thereafter decreases steadily between 60 days and 90 days. This could be as a result of protective film formed on the surface of the corroding samples, which prevented further corrosion. This behavior agrees with the findings in [26], they observed that the corrosion rate of medium carbon steel and carbon steel in general decreases with exposure time as protective barrier films are formed on the steel surface which effectively prevented corrosive medium from coming into contact with the steel and greatly reduces the corrosion rate. It could be seen that the same trend of corrosion rate hold for all the specimens. It can be seen that the corrosion susceptibility of the medium carbon steel samples increases with increase in tempering temperatures throughout the exposure time. This may be attributed to precipitation of carbide at the grain boundaries of this steel samples which eventually become susceptible to attack by the corrosion medium. The higher the tempering temperature, the more the carbide precipitated at the grain boundaries, and hence the more the corrosion attack by the medium which is in agreement with the findings in [20] and [27], they observed that the higher the tempering temperature, the more the carbide precipitated at the grain boundaries, and hence the more the corrosion attack by the medium. It was also observed that the $250{ }^{\circ} \mathrm{C}$ tempered steel sample behaved better in the corrosion medium than the other tempered samples of higher tempering temperatures.

3.2.2 Optical and SEM Evaluation of the Microstructural Changes of the Varied Tempering Temperatures on Corrosion Rate

Fig. 2 show the microstructure of the control sample after immersion in $\mathrm{NaCl}$ solution for 90 days. Visible rust layer on the surface appears in dark contrast or reddish contrast due to high oxygen content which is in accordance with the findings in [20] where it was stated that after a certain period, corrosion selects another path and anodic dissolution starts along the laths within the matrix. Finally, the rust layer on the surface appears in dark contrast or reddish contrast due to high oxygen content. Fig. 3 - Fig. 6 show the microstructure of the tempered samples after immersion in $\mathrm{NaCl}$ solution for 90 days. It can be seen from these figures that the increase in tempering temperatures result in more coarse microstructures due to the availability of thermal energy needed for the precipitation of carbides. Fig. 3 tempered at $250{ }^{\circ} \mathrm{C}$ show least coarse microstructure with Fig. 6 showing the coarsest microstructure for the tempered samples. Sample tempered at $250{ }^{\circ} \mathrm{C}$ has a higher corrosion resistance compare to others tempered at higher temperatures. The Lath type ferrite and cementite phases within the $250{ }^{\circ} \mathrm{C}$ tempered sample are responsible for the low corrosion rate. This is justified by the findings in [20] where it was stated that steel tempered at lower temperature has a higher corrosion resistance compared to steel tempered at higher temperature. Lath type ferrite and cementite phases

Vol. 37, No. 3, July, 2018 
within steel tempered at lower temperature are responsible for the low corrosion rate. The increase in corrosion rates can be attributed to the increase in carbide precipitation due to the formation of micro galvanic cells within the microstructure with the carbide phase becoming cathodic and the ferrite anodic. This is in agreement with the findings in [1] where it was stated that the observable difference in corrosion rates could be attributed to precipitation of ferrite and carbide phases.

Fig. 7 - Figure. 11 show SEM micrographs of control sample and tempered samples at various temperatures after immersion in $\mathrm{NaCl}$ solution for 90 days. The morphology of the samples showed the presence of uniform corrosion across all the samples and the formation on the surface corrosion products as scales in different sizes with the control and $550{ }^{\circ} \mathrm{C}$ tempered sample showing a little crack propagation which may have resulted from mild pit formation due to the $\mathrm{Cl}^{-}$ion present in the corrosive medium. This corresponds to the findings in [20], where it was stated that it is certain that the steel having soft matrix, anodically dissolves with the interaction of $\mathrm{Cl}^{-}$ion as function of time. The lowest corrosion resistance showed samples which is related to the precipitation of the carbides at the grain boundaries (Figure 11). The highest corrosion resistance has been established in samples after tempering at temperature $250{ }^{\circ} \mathrm{C}$ (Figure 8).

\section{CONCLUSION}

From the results of the investigation carried out, the following conclusions were made:

1. The corrosion rate increases with increasing tempering temperatures in $\mathrm{NaCl}$ environment and this was due to the precipitation of carbides at the grain boundaries of these metals.

2. The Control sample were more susceptible to corrosion than the heat treated medium carbon steel samples in $\mathrm{NaCl}$ solution.

3. The least tempered sample $\left(250{ }^{\circ} \mathrm{C}\right)$ showed a higher resistance to corrosion in $\mathrm{NaCl}$ environment than $350{ }^{\circ} \mathrm{C}, 450^{\circ} \mathrm{C}$, and $550{ }^{\circ} \mathrm{C}$ tempered samples, which revealed that, it is best to be used in this medium compared to other tempered samples and control sample.

\section{REFERENCES}

[1] Igwenmezie, V. C. and Ovri, J. E. O. Investigation into the effects of microstructure on the corrosion susceptibility of medium carbon steel. IJES,2(6), pp.11-26. 2013.
[2] Wernick, I. K. and Ausubel, J. H. National materials flows and the environment. Annual Review of Energy and the Environment, 20(1), pp.463-492. 1995.

[3] Alo, F. I., Oluyamo, S. S., Faromika, O. P., Atanda, P. O., Daniyan, A. A. and Oluwasegun, K. M. The Study of Wear and Corrosion Properties of Two Grades of Carbon Steel Used in Construction Industries in Nigeria. International Journal of Materials Engineering, 7(4), pp.77-82. 2017.

[4] DeGarmo, E. P., Black, J. T., Kohser, R. A. and Klamecki, B. E. Materials and process in manufacturing. Prentice Hall. 1997.

[5] Rakhit, A. K. Heat treatment of gears: a practical guide for engineers. ASM international. 2000.

[6] Davis, J. R. ed. Alloying: understanding the basics. ASM international. 2001.

[7] Callister W. D. Jr. Fundamentals of Materials science and Engineering. $4^{\text {th }}$ Edition, Choudhary press, New Delhi. 2011.

[8] Onyekpe, B. The Essentials of Metallurgy and Materials in Engineering. ISBN 978 8016-53-7, Ambik Press, Nigeria. 2002.

[9] Shifler, D. A. "Understanding material interactions in marine environments to promote extended structural life". Corrosion Science, 47(10), pp.2335-2352. 2005.

[10] Angst, U., Elsener, B., Larsen, C.K. and Vennesland, $\emptyset$. "Critical chloride content in reinforced concrete-a review". Cement and concrete research, 39(12), pp.1122-1138. 2009.

[11] Shifler, D. A. and Aylor, D. M. "Considerations for the Testing of Materials and Components in Seawater". CORROSION 2002. NACE International. 2002.

[12] Huang, Y. R., Hung, Y. C., Hsu, S. Y., Huang, Y. W. and Hwang, D. F. "Application of electrolyzed water in the food industry". Food control, 19(4), pp.329-345. 2008.

[13] Cassano, A., Molinari, R., Romano, M. and Drioli, E. "Treatment of aqueous effluents of the leather industry by membrane processes: a review". Journal of Membrane Science, 181(1), pp.111-126. 2001.

[14] Caenn, R., Darley, H. C. and Gray, G. R. "Composition and properties of drilling and completion fluids". Gulf professional publishing. 2011.

[15] Monteiro E. N., P. R. Ribeiro, and R.F.T. Lomba. "Study of the PVT Properties of Gas Synthetic Drilling-Fluid Mixtures Applied to Well Control", SPE Drilling and Completion, March 2010, vol.25, No.1, pp.45-52. 2010. 
[16] Arya, C., Buenfeld, N. R. and Newman, J. B. "Factors influencing chloride-binding in concrete". Cement and Concrete research, 20(2), pp.291-300. 1990.

[17] Ramezanianpour, A. A. and Malhotra, V. M. "Effect of curing on the compressive strength, resistance to chloride-ion penetration and porosity of concretes incorporating slag, fly ash or silica fume". Cement and concrete composites, 17(2), pp.125-133. 1995.

[18] Mason, B. J. "The role of sea-salt particles as cloud condensation nuclei over the remote oceans". The Quarterly Journal of the Royal Meteorological Society, 127 (576): 2023-32. 2006.

[19] Atanda, P. O., Olorunniwo, O. E., Alabi, O. D, and Oluwole, 0. 0. "Effect of Iso-Thermal Treatment on the Corrosion Behaviour of Low Carbon Steel (Nigerian C2R grade) in a Buffered Solution containing Chloride and Carbonate Ions". International Journal of Materials and Chemistry, 2(2), pp. 65-71. 2012.

[20] Atapek, S. H., Seyda, P., and Sibel, Z. "Effect of Tempering Temperature and Microstructure on the Corrosion Behavior of a Tempered Steel". Protection of Metals and Physical Chemistry of Surfaces, Vol. 49, No. 2, pp. 240-246. 2013.

[21] Atık, E., Yunker, U. and Merıç, C. "The effects of conventional heat treatment and boronizing on abrasive wear and corrosion of SAE 1010, SAE 1040, D2 and 304 steels". Tribology International, 36(3), pp.155-161. 2003.
[22] Daramola, 0. 0., Adewuyi, B. 0., \& Oladele, I. 0. "Corrosion Behaviour of Heat Treated Rolled Medium Carbon Steel in Marine Environment". Journal of Minerals \& Materials Characterization \& Engineering, Vol. 10, No.10, pp. 888-903. 2011.

[23] Larrabee, C.P. "Corrosion-resistant experimental steels for marine applications". Corrosion, 14(11), pp.21-24. 1958.

[24] Li, Y., Hou, B., Li, H. and Zhang, J. "Corrosion behavior of steel in Chengdao offshore oil exploitation area". Materials and Corrosion, 55(4), pp.305-310. 2004.

[25] Omotoyinbo, J. A., Oloruntoba, D. T., and Olusegun, S. J. "Corrosion Inhibition of Pulverized Jatropha Curcas Leaves on Medium Carbon Steel in 0.5 M $\mathrm{H}_{2} \mathrm{SO}_{4}$ and $\mathrm{NaCl}$ Environments". International Journal of Science and Technology, Volume 2, No. 7, pp. 510-514. 2013.

[26] David, A. S and Denise, M. A. "Seawater" In: Robert B. (ed). Corrosion Test and Standards: Application and Interpretation. 2nd Edition, Baltimore, ASTM International, pp. 362-379. 2005.

[27] Afolabi, A. S., Johannes, H. P., Ambali, S. A., and Nonhlanhla, F. "Effect of Tempering Temperature and Time on the Corrosion Behaviour of 304 and 316 Austenitic Stainless Steels in Oxalic Acid". World Academy of Science, Engineering and Technology. International Journal of Materials and Metallurgical Engineering. Vol. 5, No. 7, pp. 528532. 2011. 